\title{
Kekerasaan Seksual di Mata Konde (Analisis Framing Kekerasaan Seksual terhadap Perempuan pada Rubrik Perspektif Konde Edisi November dan Desember 2018)
}

\author{
Martalena, Gafar Yoetadi \\ martalena84.mp@gmail.com,gafary@fikom.untar.ac.id \\ Fakultas Ilmu Komunikasi Universitas Tarumanagara
}

\begin{abstract}
This study discusses the framing analysis of the violence of the section on women in the November and December 2018 editions. In the violence analysis of the women's section using the method of framing analysis of the Robet N. Entman model with qualitative research methods. Five articles from the Perse Perspective rubric explain Konde's side to women as victims of sexy abuse. Clearly this era of the development of communication is getting faster and can be obtained at any time. This caused the inflow of mainstream news to become increasingly out of control. Konde is present as an alternative media that constructs news realities that show partiality towards women victims of sexual violence and survivors. In framing the news Konde shows partisanship for women to provide space for expression with their capacity. In addition, Konde frames the news that gives news treats to readers about sexual violence should be given the opportunity to get themselves.
\end{abstract}

Keywords: Framing Analysis, Construction of Reality, Konde, Mass Communication

\begin{abstract}
Abstrak
Penelitian ini membahas analisis framing tentang kekerasaan seksual terhadap perempuan edisi bulan November dan Desember 2018. Dalam analisis kekerasaan seksual perempuan menggunakan metode analisis framing model Robet N. Entman dengan metode penelitian kualitatif. Lima artikel Konde pada Rubrik Perspektif menjelaskan bahwa keberpihakan Konde berada pada perempuan sebagai korban pelecehan seksual. Terlihat jelas era ini perkembangan komunikasi massa semakin cepat dan dapat diperoleh kapan saja. Hal ini menyebabkan arus masuknya berita-berita mainstream semakin tak terkendali. Konde hadir sebagai media alternatif yang mengkonstruksikan realitas berita yang menunjukkan keberpihakan terhadap perempuan korban kekerasan seksual dan kaum penyintas. Dalam membingkai berita, Konde menunjukan keberpihakan pada perempuan untuk memberikan ruang ekspresi dengan kapasitasnya. Selain itu, Konde membingkai berita yang memberikan suguhan berita kepada pembaca bahwa korban kekerasaan seksual harus diberikan kesempatan untuk membela diri.
\end{abstract}

Kata Kunci: Analisis Framing, Kontruksi Realitas, Konde, Komunikasi Massa 


\section{Pendahuluan}

Tindakan kekerasaan terhadap perempuan setiap tahunnya selalu mengalami peningkatan, tidak hanya kekerasaan fisik saja yang dialami perempuan tetapi kekerasaan seksual pun turut dialami. Seperti yang telah dilansir pada website komnasperempuan.go.id dalam tiga tahun terakhir, korban kekerasan seksual pada perempuan mengalami peningkatan, di mana pada tahun 2015 yaitu 1.657 kasus, tahun 2016 yaitu 2.290, tahun 2017 yaitu 2.979 kasus, dan pada tahun 2018 kekerasaan seksual meningkat sebesar $14 \%$ tetapi tidak ada keterangan jumlah pasti keseluruhan kekerasaan seksual pada tahun 2018.

Sementara itu, menurut website resmi komnasperempuan.go.id terdapat 15 bentuk kekerasaan seksual. Sementara, kekerasaan seksual tampil di media dengan dua mata pisau. Pada satu sisi, pemberitaan terkait kekerasaan seksual ini dimaksudkan untuk menimbulkan efek jera bagi pelaku sehingga kejadian yang sama tidak terulang lagi. Namun, di sisi lain mayoritas korban kekerasaan seksual menjadi korban untuk kedua kalinya saat diberitakan media.

Dalam laporan analisa media Komnas Perempuan bertajuk Sejauh Mana Media Telah Memiliki perspektif Korban Kekerasaan Seksual? Riset ini memantau sembilan media dan menemukan 225 berita yang berhubungan dengan kekerasaan seksual. Jumlah ini merupakan 18,17 persen dari total 1.238 berita yang dirilis dari sembilan media tersebut. Saat ini sedikit media yang sadar mengenai isi pada berita kasus pelecehan seksual itu penting, dan artikel dibuat dapat dilihat dari berbagai sisi. Namun, tidak sedikit media yang memberitakan dengan stigma korban sebagai pemicu kekerasaan seksual.

Hal ini dapat dilihat dari salah satu komponen pada berita yakni memperhatikan pemenuhan hak korban menurut Komnas Perempuan yaitu faktor stigmatisasi korban sebagai pemicu kekerasan. Dari 225 total berita, terdapat 41 berita yang menyebutkan korban sebagai pemicu terjadinya kekerasan. Selain itu, 24 berita bernada menghakimi korban dan 28 berita melanggengkan stereotip terhadap korban.

Konde lahir sebagai media alternatif berbasis online yang diinisiasi oleh sejumlah individu yang mempunyai keresahan yang sama mengenai marjinalisasi, diskriminasi, subordinasi, kekerasaan, dan stigma yang negatif terhadap perempuan dan masyarakat marjinal dan mengubahnya melalui media. Melalui tulisan, Konde menghadirkan gagasan untuk mengelola ruang publik dari sudut pandang perempuan dan masyarakat marjinal yang memberikan pemahaman, pencerahan, kesadaran, dan daya kritis masyarakat.

Konde merupakan aktivitas yang dikelola oleh sejumlah individu melalui perkumpulan bernama: konde institusi, sebuah perkumpulan yang memperjuangkan kebebasan berekspresi, berserikat, dan berpendapat bagi perempuan dan kelompok marjinal di media.

Konde memiliki dua rubrik, yaitu Rubrik Perspektif dan Rubrik Peristiwa. Rubrik Perspektif adalah tulisan/foto yang dibuat berdasarkan ide/gagasan tentang isu perempuan dan isu masyarakat marjinal.

Pada Rubrik Peristiwa, berisi berita/ foto tentang peristiwa, kejadian yang menimpa perempuan atau profil, interview, resensi buku, film dan lain lain, dilakukan oleh para perempuan dan kelompok marjinal. Berita dan foto bisa merupakan peristiwa di Indonesia maupun luar negeri yang bisa ditulis dan difoto oleh masyarakat sendiri sebagai bagian dari jurnalisme warga. 
Dengan latar belakang yang disebutkan di atas, penulis melakukan penelitian berjudul, "Kekerasan Seksual di Mata Konde (Analisis Framing Kekerasan Seksual terhadap Perempuan pada Rubrik Perspektif Konde Edisi November dan Desember 2018)".

\section{Metode Penelitian}

Penulis menggunakan metode analisis framing model Robert N. Entman. Konsep framing, pada Robert N. Entmant digunakan saat menggambarkan proses seleksi dan menonjolkan aspek tertentu dari realitas oleh media. Framing dapat dipandang sebagai penempatan informasi-informasi dalam konteks yang khas sehingga isu tertentu mendapatkan alokasi lebih besar daripada isu yang lain (Eriyanto, 20002:220).

Analisis wacana framing bertugas menemukan perspektif media dalam wacana. Pada umumnya menarget language use atau bahasa yang digunakan sehari-hari, baik yang berupa teks lisan maupun tertulis sebagai objek kajian atau penelitiannya (Purbani, $2005:$ 1). Analisis framing yang digunakan dalam penelitian ini adalah analisis framing model Robert N. Entman.

\section{Hasil Temuan dan Diskusi}

\section{Artikel Kita Bersama Agni}

Kasus Agni menunjukkan masyarakat merespon baik keberanian korban mengupayakan keadilan bagi dirinya. Pada artikel dibuktikan di paragraf tiga terdapat statement Perempuan Mahardhika dalam akun instagramnya untuk Agni: "Agni, kamu tidak sendiri Agni telah memilih untuk jadi berani. Hal ini menepis segala rasa takut akan serangan-serangan balik bagi korban ia bersuara." Pada artikel ini pesan yang disampaikan bersifat umum dan fakta. Adapun Konde menyampaikan pesan bersifat opini ditujukan pada pembaca mahasiswa, pekerja, serta setiap perempuan yang telah dewasa. Sejumlah tagar lain juga mengajak untuk mengekspresikan dukungan untuk Agni.

Instagram Pokja buruh perempuan mem-posting: "bagi yang tidak bisa mengikuti aksi dukungan terhadap Agni secara langsung, mari kita ekspresikan dukungan untuk Agni dan kawan-kawan \#kitaagni melalui swafoto dengan poster." Dengan harapan pembaca dapat turut berpartisipasi memberi dukungan. Artikel ini menunjukan bahwa adanya karakteristik komunikasi massa, karena pesan berupa fakta yang menjadikan ini sebuah ciri dari komunikasi massa, yaitu pesan bersifat umum, pesan yang bersifat terbuka yang ditujukan pada suatu kelompok. Pesan komunikasi massa dapat berupak fakta, peristiwa atau opini (Ardianto dkk, 2007).

Selain itu, karena targetnya adalah para pembaca, masyarakat hanya dapat melihat teks dan gambar/foto yang ditampilkan di website maka termasuk dalam karakteristik kedua yaitu stimulasi alat indera terbatas. Stimulasi dalam alat indera ini bergantung pada jenis media massa. Pada media cetak, pembaca hanya melihat. Pada siaran radio, audiens hanya mendengar, sedangkan pada media televisi dan film, audiens menggunakan indra penglihatan dan pendengaran (Ardianto dkk, 2007).

Pada sudut pandang Konde, artikel ini menunjukkan bahwa masih pada peristiwa yang dialami Agni, masyarakat diajak untuk memberikan dukungannya. Hal ini agar kasus yang dialami Agni tidak terulang lagi kepada Agni yang lain. Konde mengonsep artikelnya pada pandangan sangat perlu untuk masyarakat memberikan 
dukungan masif seperti pada dukung Agni dan setiap perempuan yang menjadi korban kekerasaan seksual. Dibuktikan pada paragraf delapan yaitu, gerakan masif ini sangat penting untuk mendukung Agni dan setiap perempuan yang menjadi korban kekerasan seksual. Konde dalam melakukan konstruksi artikelnya melihat sisi keberpihakannya kepada Agni sebagai korban. Artikel ini berkaitan pada teori konstruksi realitas merupakan konsep bagaimana menceritakan, mengonseptualisasikan peristiwa, suatu keadaan, dan sesuatu benda. Sementara setiap aktor sosial berperan dalam proses konstruksi realitas ini, termaksud pada media massa (Karma, 2012:27).

Selain itu, Rubrik Perspektif Konde pada artikelnya memasukkan beberapa teori mengenai kekerasaan seksual seperti pada paragraf sembilan, tindakan kekerasan seksual merupakan kejahatan, feminis Andrea Dworkin menuliskan bahwa perkosaan atau kekerasan seksual adalah tindakan agresi yang merupakan kejahatan hak milik atau kejahatan politik. Artikel tersebut semata tidak hanya melihat perspektif Konde saja sebagai agen konstruksi, tetapi mengambil teori dari feminis sebagai pilihan kata dan cara penyajian, karena suatu realitas turut menentukan bentuk konstruksi realitas yang sekaligus menentukan makna yang muncul darinya. Bahkan menurut Hamad (2001:57) bahasa bukan hanya mampu mencerminkan realitas, tetapi sekaligus menciptakan realitas.

\section{Artikel Tuti Tursilawati, Pembelaan Diri yang Berujung Eksekusi Mati}

Artikel ini menunjukan pesan perspektif Konde yang ingin disampaikan kepada pembaca bahwa Tuti Tursilawati tidak hanya sebagai pelaku, tetapi juga sebagai korban yang mengalami percobaan perkosaan oleh majikannya. Hal ini agar pembaca semata tidak menyalahkan Tuti sebagai pelaku yang sepenuhnya salah, tetapi ada hal tersembunyi yang perlu diketahui pembaca. Dibuktikan pada paragraf tiga kalimat dua pernyataan terhadap kasus Tuti yakni, Anis Hidayah dari Migrant Care yang melakukan pendampingan hukum pada kasus Tuti menyatakan bahwa sistem hukum di Arab Saudi tidak memberikan ruang untuk pasal pembelaan diri. Padahal Tuti sedang dalam melakukan pembelaan dirinya ketika peristiwa ini terjadi.

Hal ini membuktikan bahwa ada isi pesan yang perlu diketahui masyarakat terhadap kasus Tuti. Terlihat bahwa selain tidak diberi ruang untuk mengeluarkan pendapat yang membela dirinya, Tuti juga tidak mendapatkan perlindungan hukum. Adapun di paragraf keempat pernyataan yang dapat membenarkan dirinya sepenuhnya tidak bersalah yakni, "Ini menjadi sangat ironis karena Tuti selalu dalam kondisi tertekan, dia mengalami percobaan perkosaan dan ancaman kekerasan dari majikannya," ujar Anis Hidayah dalam aksi bersama di Kedubes Arab Saudi pada Jumat, 2 November 2018 di Jakarta. Pesan yang disampaikan ini merupakan bentuk dari komunikasi massa. Komunikasi massa yang paling sederhana diungkapkan oleh Bitnner (dalam Rahmat, 2007:3). Definisi komunikasi massa ialah pesan yang dikomunikasikan melalui media massa pada sejumlah besar orang (mass communication is massages communicated through a mass medium to a large number of people).

Aritkel ini memaparkan bahwa peran media alternatif di media Konde terjalankan, seperti pada kasus Tuti yang mendapatkan diskriminasi dirinya bersalah sepenuhnya. Tetapi Konde membuka fakta, bahwa setelah Tuti dijatuhi hukuman mati, dan jenazah akan di masukkan ke liang lahat keluarga tidak dapat melihat jenazah Tuti. Ini dibuktikan pada paragraf lima yakni, Usman Hamid, Direktur Amnesty Indonesia bahkan menyatakan bahwa ketika jenasah Tuti akan dimasukkan ke liang lihat, keluarga Tuti tidak diperbolehkan untuk melihat jenasah. Ini merupakan perbuatan keji 
yang sama sekali tidak memberikan ruang apapun untuk kemanusiaan. Terlihat jelas bawah diskriminasi terhadap perempuan yang mengalami percobaan perkosaan terjadi, bahkan hingga ke buruh migran. Tidak ada kejelasan payung hukum yang melindungi kaum buruh dari hukum Arab Saudi. Melihat keberpihakan perspektif Konde pada Tuti, yang menampilkan artikel berbeda dengan media mainstream. Namun, menggunakan media alternatif yang terbentuk dari realitas yang dibangun dan dikonstruksikan oleh media massa. Media alternatif merupakan media pilihan masyarakat untuk memperoleh informasi yang akurat, benar, dan tidak memihak. Media ini diharapkan dapat melayani kelompok yang sesungguhnya mayoritas tetapi termajinalisasi (Birowo, $2004: 135$ ).

\section{Artikel Kuatnya Budaya Victim Blaming Hambatan \#MeToo}

Perspektif Konde pada artikel ini membahas gerakan \#MeToo merupakan gerekan aksi solidaritas terhadap korban kekerasaan. Namun, adanya budaya victim blaming yakni budaya yang menyalahkan korban membuat perempuan Indonesia bungkam sebagai saksi kasus pelecehan seksual. Akan tetapi, budaya ini dapat diruntuhkan di negara Amerika Serikat sehingga para perempuan dapat bersaksi atas kasus kekerasaan seksual yang dialaminya. Ini menunjukan perspektif artikel ketiga Konde berperan sebagai media alternatif berdasarkan teori media alternatif yaitu kita bisa mengambil dasar tersebut dengan mengatakan bahwa media alternatif akan selalu berusaha memberikan yang berbeda dari apa yang dihasilkan oleh media mainstream. Tujuannya sudah jelas sebagai referensi tambahan atau bahkan referensi yang berlawanan kepada khalayak (Wahyudi, 2011).

Konde memaparkan masalah terhadap adanya victim blaming membuat perempuan sulit untuk memberi kesaksian. Korban yang harusnya memiliki hak untuk memberi kesaksian dan membela dirinya justru dipersalahkan. Hal ini membuat gerakan aksi \#MeToo. Terlihat pada paragraf 13 yang artikelnya menyatakan, Victim blaming merupakan bentuk tindakan yang menyalahkan perempuan terhadap kekerasan seksual yang mereka alami. Hal ini dari dilihat dari kasus cenderung berpihak pada para pelaku. Masyarakat juga lebih banyak mendengarkan cerita versi pelaku.

Paragraf dua menyatakan fakta gerakan aksi \#MeToo yaitu, di Indonesia, perempuan turut andil dalam melakukan gerak aksi solidaritas kepada korban kekerasan atau yang dikenal dengan gerakan \#MeToo. Penggerak aksi ini yaitu para korban kekerasan seksual yang melaporkan kasus yang dilakukan pelaku pada polisi. Perspektif Konde pada artikel ini menjelaskan bahwa peran media sangat penting. Media memiliki peran ganda dalam kasus kekerasan seksual. Pada satu sisi, media adalah sumber informasi utama bagi masyarakat untuk memperoleh informasi terhadap adanya kekerasan perempuan. Sementara, di sisi lain media menjadi salah satu sarana edukasi masyarakat dalam menyikapi kekerasan seksual. Media juga bisa memberi tempat agar suara penyintas didengar. Konde mengambil contoh kasus pada laporan Balairung tentang perkosaan Agni di UGM misalnya, telah menarik perhatian dan simpati publik atas kejadian tersebut. Konde memainkan peran edukasi yang berbeda, mendukung penyintas kekerasaan seksual. Berdasarkan teori konstruksi inilah cara media Konde yaitu konstruksi realitas pada prinsipnya merupakan konsep yang, mengonseptualisasikan peristiwa, menceritakan, suatu keadaan, dan benda. Setiap aktor sosial mengambil peran dalam proses konstruksi realitas ini, termasuk media massa (Karma, 2012:27). 
Artikel ini berdasarkan teori analisis kekerasaan seksual terhadap perempuan tidak sepenuhnya membahas satu topik kasus kekerasaan seksual tetapi beberapa perempuan yang mengalami kekerasaan seksual atau perkosaan dan terpapar budaya victim blaming. Kasus ini berkaitan kembali kepada jenis pertama kekerasaan seksual terhadap perempuan berdasarkan Komnasperempuan.go.id yaitu: Perkosaan adalah serangan yang diarahkan pada bagian seksual dan seksualitas seseorang dengan menggunakan organ seksual (penis) ke organ seksual (vagina), anus atau mulut, atau dengan menggunakan bagian tubuh lainnya.

\section{Artikel 5 Alasan Kenapa Perkawinan Anak Harus Dilarang}

Sebagai media alternatif, Konde membahas perkawinan anak dari sudut pandang lain. Media mainstream dalam menampilkan isi konten yang menayangkan tentang perkawinan anak di bawah umur, justru dipandang sebagai hal yang unik dari budaya. Tetapi Konde sebagai media alternatif menentang adanya pernikahan anak, dengan menampilkan beberapa fakta yang berdampak negatif pada pernikahan anak. Paparan di atas berdasarkan teori media alternatif menjelaskan media alternatif merupakan media pilihan masyarakat untuk memperoleh informasi yang akurat, benar, dan tidak memihak. Media ini diharapkan dapat melayani kelompok yang sesungguhnya mayoritas tetapi termajinalisasi (Birowo, 2004 : 135).

Konde dalam mengkonstruksi artikel berita memaparkan keadaan sesungguhnya pada dampak yang dirasakan jika melakukan pernikahan anak. Pandangan Konde tidak semata semua kasus menjadi berita tanpa di telaah secara mendalam. Seperti memberitakan pernikahan anak, Perspektif Konde melihat sudut pandang yang berbeda dari media mainstream. Terbukti pada bagian artikel yang membahas, "Mengapa harus dilarang?" terlihat jelas bahwa Perspektif Konde tidak setuju adanya pernikah anak. Berdasarkan paparan di atas berkaitan dengan istilah Contructivism oleh Littlejohn dipakai untuk menjelaskan suatu teori yang menyatakan bahwa setiap individu menafsirkan sesuatu dan berperilaku menurut kategori-kategori konseptual dari pikirannya. Realitas tidaklah muncul begitu saja dalam bentuk mentah melainkan harus disaring sesuai cara pandang seseorang mengenai setiap hal yang ada (Karma, 2012 : 29).

Perkawinan anak secara paksa merupakan kekerasaan seksual. Konde yang merupakan media alternatif yang menolak kekerasaan seksual terhadap perempuan, memberikan Perspektif penolakan terhadap perkawinan anak. Teori yang menyatakan pernikahan anak secara paksa merupaka kekerasaan seksual berdasarkan Komnasperempuan.go.id yang mengacu pada jenis-jenis kekerasaan seksual nomer 12 yang isinya, pemaksaan perkawinan, termasuk kawin paksa dan kawin gantung adalah situasi dimana perempuan terikat perkawinan di luar kehendaknya sendiri, termasuk di dalamnya situasi di mana perempuan merasa tidak memiliki pilihan lain kecuali mengikuti kehendak orang tuanya untuk tujuan mengurangi beban ekonomi keluarga maupun tujuan lainnya. 


\section{Simpulan}

Sebagai media alternatif salah satu hal yang tidak mudah untuk dapat dikenal dan mendapatkan pembaca. Tidak hanya itu saja, untuk dapat bertahan di tengah arus media mainstream tentu sangat sulit. Tidak sedikit diantaranya turut menggunakan dana pribadi. Media alternatif tidak melakukan pemberitaan hanya demi mendapatkan pembaca dan keuntungan komersial. Tetapi untuk mampu memberikan suara kepada kaum minoritas khususnya kekerasaan seksual terhadap perempuan.

Konde berdiri sebagai media alternatif yang setiap artikel menyampaikan sudut pandang yang berbeda dengan media mainstream umumnya. Seperti menentang kekerasan terhadap perempuan, khususnya menentang kekerasan seksual. Jelas sekali paparan pada pembahasan di bab sebelumnya melihatkan ideologi Konde sebagai media alternatif. Gagasan atau sudut pandang Konde selama mengkonstruksikan realitas membela kaum-kaum penyintas. Korban kekeraaan seksual yang seharusnya mendapatkan perlindungan hukum, justru dipersalahkan. Di sinilah media Konde memaparkan ideologi atas tekanan mayoritas kepada penyintas.

Sebagai media alternatif Konde membingkai artikel dengan melakukan konstruksi realitas media pada Rubrik perspektif mengenai kekerasan seksual terhadap perempuan. Artikel Konde dalam membingkai berita menunjukan keberpihakannya kepada perempuan penyintas. Perempuan sebagai korban kekerasan seksual yang terpapar kasus victim blaming. Media Konde berusaha memberikan ruang kepada kaum perempuan khususnya korban pelecehan seksual yang selama ini terpaksa bungkam.

\section{Ucapan Terima Kasih}

Penulis mengucapkan terima kasih kepada pihak-pihak yang telah memberikan sumbang saran pengetahuannya, terutama pada dosen pembimbing Bapak Drs. M. Gafar Yoedtadi, M.Si yang telah memberikan saran pendapat dalam penyelesaian skripsi dan penulisan jurnal ilmiah.

\section{Daftar Pustaka}

Alex, S. (2002). Analisis Text Media. Bandung: PT. Remaja Rosda Karya .

Ardianto, E. (2007). Komunikasi Massa Suatu Pengantar. Bandung: Simbiosa Rekatama Media.

Arsyad, A. (2002 ). Media Pembelajaran. Raja Grafindo Persada.

Birowo, M. A. (2004). Melawan Hegemoni Media dengan Strategi Komunikasi Berpusat pada Masyarakat. Jurnal Ilmu Komunikasi, Volume 1 Nomor 1 135. -

Bungin, Burhan. 2011. Penelitian Kualitatif. Jakarta: Kencana Predana Media Group

Creswell, J. W. (2010). Research Design: Pendekatan Kualitatif, Kuantitatif, dan Mixed. Yogyakarta : PT. Pustaka Belajar.

Effendy, O. U. (2007). Ilmu Komunikasi: Teori dan Praktek. Bandung: PT. Remaja Rosdakarya.

Elvinaro Ardianto, L. K. (2007). Komunikasi Massa. Bandung: Simbiosa Rekatma Media.

Eriyanto. (2002). Analisis Framing. Yogyakarta: LKiS Yogyakarta.

M, R. S. (2016). Media Alternatif, Masa Depan Media Indonesia . Universitas Kristen Satya Wacana, 11. 
Rakhmat, J. (1996). Psikologi Komunikasi. Bandung: Remaja Rosdakarya. Sobur. (2012). Analisis Text Media. Bandung: Remaja Rosdakarya.

Sudibyo, A. (2001). Politik Media dan Pertarungan Wacana. Yogyakarta: LkiS. Sugiyono. (2011). Metode Penelitian Pendidikan . Bandung: Alfabeta.

Tamburaka. (2013). Agenda Setting Media Massa. Jakarta: RajaGrafindo Persada. 